\title{
Optimal Corporation Tax: An I.O. Approach
}

\author{
Luca Colombo*, Paola Labrecciosa
}

$\mathrm{EI} / 42$

January 2006
The Toyota Centre

Suntory and Toyota International Centres for Economics and Related Disciplines London School of Economics and Political Science Houghton Street London WC2A $2 \mathrm{AE}$

Tel: (020) 79556674

* Institute for International Integration Studies, The Sutherland Centre, Trinity College, Dublin, Dublin 2, Ireland; email: Colombo@tcd.ie; tel. +353-01-6083207. Dept. of Economics, University of Bologna, Strada Maggiore 45, 40125 Bologna, Italy; email: Colombo@spbo.unibo.it; tel. +39-051-2092600.

$\dagger$ Dept. of Economics, Trinity College Dublin, Dublin 2, Ireland; email: labreccp@,tcd.ie; tel. +353-1-6082325. Dept. Of Economics, University of Bologna, Strada Maggiore 45, 40125 Bologna,Italy; email: labrecciosa@spbo.unibo.it; tel. +39-051-2092600.

‡Dept. of Economics and IIIS, Trinity College Dublin, Dublin 2, Ireland; email: ppwalsh@tcd.ie; tel. +353-1-6082326. 


\begin{abstract}
Theory predicts that optimal effective corporation tax rates will be negatively related to industry specific sunk costs, and hence industry concentration. Governments should tax industries with monopolistic power softly. Evidence suggests that this Schumpeterian (1942) principle of corporate taxation was used widely across industries in France, Italy and the UK in the 1990s.
\end{abstract}

Keywords: $\quad$ Effective Corporation Tax Rate, Industry Sunk Costs, Industry Concentration.

JEL classifiers: $\quad$ H25 and L52.

(C) The authors. All rights reserved. Short sections of text, not to exceed two paragraphs, may be quoted without explicit permission provided that full credit, including $\mathbb{C}$ notice, is given to the source 


\section{Introduction}

In this paper we resurrect an important debate on the relationship between corporation tax and market power that dates back to Schumpeter (1942) and Galbraith (1973). Galbraith felt that highly concentrated industries should be taxed heavily. Corporate taxation could be used to alleviate monopolistic power. Schumpeter presents us with the opposing view and emphasizes the drawbacks of taxing powerful industries heavily. In his view, corporation taxes can create distortions in the dynamics of the industry evolution and can reduce social welfare in the long run.

The existing game theoretic models of imperfect competition add little to this debate. The reason for this is that any (proportional) tax on profits, in the short-run (fixing the number of companies), does not affect the first order conditions of profit maximization. Equilibrium prices and quantities are the same with and without taxes on profits, so the arguments that corporation taxes should be used in order to mitigate monopolistic power seem not to be relevant. Moreover, if the revenue collected by the government becomes public spending, and consumers and firms are weighted equally in the welfare function, corporation taxes are also welfare neutral. Indeed, within a traditional oligopoly model, there seems to be no reason to analyze the effects of corporate taxation. ${ }^{1}$

In this paper, using a Sutton (1991) approach to industry evolution, we investigate how optimal corporation tax should be designed in reaction to industry specific sunk costs in long run equilibrium. We first write down a general oligopoly model to show that optimal profit taxation is negatively related to industry specific sunk costs once a degree of monopolistic power survives in long run equilibrium. We then illustrate our point with an example considering a Cournot oligopoly game at the long run equilibrium. Within a Cournot oligopoly, Von Weizsäcker (1980) shows that the long run equilibrium number of firms may exceed the socially optimal number of firms. ${ }^{2}$

\footnotetext{
${ }^{1}$ The existing literature on taxation in oligopoly focuses on the different forms of commodity taxation, ad valorem and specific (see Kay and Keen, 1983; Delipalla and Keen, 1992; Anderson et al., 2001, inter alia), without taking into consideration taxation on profits.

${ }^{2}$ See also Martin (1984), Mankiw and Whinston (1986), Suzumura and Kiyono (1987). The
} 
A forward looking government will regulate entry in a way that is socially desirable with corporate taxation. In the short-run, taking the number of companies as a given, profit tax has a neutral effect on quantity and price outcomes in oligopoly. However, corporation tax has implications for the evolution of market structure, a point neglected by the existing academic literature. Clearly, the number of firms operating in long run equilibrium can be affected by the level of profit taxation. Such dynamics, if understood by a perfectly informed forward looking government, should be taken into account in the design of optimal corporation tax. ${ }^{3}$ By focussing on the influence of corporation tax on market structure, our study shows that industries characterized by high sunk costs, which are ceteris paribus, linked to concentrated industries, should be taxed softly. On the contrary, when sunk costs are low, the opposite holds true. ${ }^{4}$ The principle of taxation highlighted in this paper is analogous to that found in Ramsey (1927) pricing. The interaction of imperfect competition, strategic reactions of players in the industry, with policy instruments, can create large tendency toward excessive entry in Cournot equilibrium is due to the "business stealing" effect. In such markets, the profit maximizing entry decision of individual firms does not consider the negative externality that entry imposes on incumbent firms. The resulting equilibrium number of firms is excessive from a social point of view.

${ }^{3}$ In case of commodity taxation, the issue of entry in oligopoly has been considered in Auberbach and Hines (2002), based on earlier work by Seade (1980a; 1980b), Besley (1989), Myles (1989), Delipalla and Keen (1992) and de Meza, Maloney and Myles (1995). We could also consider commodity taxation but our focus is on profit (or corporation) tax in isolation because, despite its relevance in the real world, there is no theoretical reason for this tax in oligopoly (short-run equilibrium neutrality). As we point out, it does shape long run equilibrium structures.

${ }^{4}$ Our theory will predict different rates of taxation for different industries. In reality corporate tax rate is the same for all industries it is the effective corporation tax rates across industries that are different. This results from heterogeneity in the take up of tax allowances, exemptions, and exclusions designed by government. In the real world we see that high-tech industries to pay less tax, we explain why. In long run equilibrium, the number of firms in the industry reflects the condition that ex-post entry profits equal sunk cost expenditure. Two instruments are available to the Government, tax profit differently or give different tax offsets (credits) against the nature of sunk costs (for example R\&D), in the end, it the same thing. The theory section of the paper focuses on different taxation rates but it easy to the equivalence of taxation and credits in this framework. Hence we work with effective taxation in the empirical section. 
distortions as a by product of government intervention. The more monopolistic power in an industry the bigger these distortions. Hence a forward looking government is forced to internalize this and will tax industries will higher sunk costs (monopolistic power) less. ${ }^{5}$ In our empirically sections we provide suggestive evidence that this Schumpeterian (1942) principle of taxation was used in France, Italy and the UK. ${ }^{6}$

\section{Theory}

\section{A. The Model}

The economy is composed by $M$ industries. The inverse market demand in industry $j=\{1,2,3, \ldots, M\}$ is given by a function $p_{j}: R_{+} \rightarrow R_{+}$, with $p_{j}^{\prime}<0$ and $p_{j}^{\prime \prime}>$ 0 . Every firm operating in industry $j$ is assumed to posses the same production technology exhibiting constant returns to scale; $k_{j} \geq 0$ is the unit cost of production. Industry $j$ 's output is $Q_{j}=\sum_{i=1}^{n_{j}} q_{i j}$, where $q_{i j}$ represents the quantity produced by

\footnotetext{
${ }^{5}$ Walsh and Whelan (1999) highlight the dangers of government policy (ban on loss leading in supermarkets) that try to move industries from second towards first best outcomes in the presence of endogenous imperfect competition. The interaction of imperfect competition, strategic reactions of players in the industry, with policy instruments, if unanticipated, can move you back to a third best outcome.

${ }^{6}$ In large economies the majority of tax income from corporate taxation come from large indigenous industries. For this reason we are happy to focus on an industry specific explanations for differences in effective corporation taxation. Vandenbusshe and Tan (2005), focusing on company specific effects, show that foreign owned companies have more favorable effective corporate taxation relative to home companies. They show how multinationals can use outside options to bargain down taxation with local governments. Allowing for open economy considerations in the design of corporation taxes would be an interesting extension to our framework. We feel that tax competition over interregional or international investment flows would reinforce the incentive to tax high sunk cost industries ever softer. There are many US and European studies that measure the sensitivity of investment flows to corporate taxation. Deasi et al (2002), Hines (1999), Grubert and Mutti (1991) and Altshuler et al (1998). In addition, there maybe an interesting interaction of open economy considerations and industry specific tax allowances and exceptions that would have implications on the financing of multinational corporations. One nice thing about our set-up is that we do have an outside option in the model which could easily used to allow for two region model to address the issue of (international) tax competition. We feel that cross border competition would reinforce our results.
} 
firm $i=\left\{1,2,3, \ldots, n_{i}\right\}$ in the $j-t h$ industry. Gross operative profits (before tax) for a generic firm in industry $j$ are then given by:

$$
\pi_{i j}=\left(p_{j}-k_{j}\right) q_{i j}
$$

In every industry, the government imposes a proportional corporate income tax $\tau_{j} \in(0,1)$ on each firm's operative profits. Net profits (after tax) correspond to $\left(1-\tau_{j}\right) \pi_{i j}$. For each firm entering industry $j$, there is an entry (set up) sunk cost equal to $F_{j}>0$. Once in the market, the firm $i$ s s problem consists in setting $q_{i j}$ so as to maximize its profits. The first order condition of firm $i$ 's problem turns out to be (assuming an inner solution exists):

$$
\left(1-\tau_{j}\right)\left[p_{j}^{\prime}\left(1+\theta_{j}\right) q_{i j}+p_{j}-k_{j}\right]=0
$$

where $\theta_{j}=d Q_{-i j} / d q_{i j}$, as in Bresnahan (1989), takes on a value between zero and one. It determines how much marginal revenue falls due to price competition increasing as output expands. If we define $\lambda_{j}=1+\theta_{j}, \lambda_{j} \in\left[0, n_{j}\right]$ captures firms' strategic interactions in industry $j$. With $\lambda_{j}=0$, conjectures are competitive in industry $j$; $\lambda_{j}=1$ corresponds to Cournot conjectures and $\lambda_{j}=n_{j}$ corresponds to tacit collusion in industry $j$.

Notice that the term $1-\tau_{j}$ can be canceled out, meaning that the profit maximizing quantity chosen by each firm does not depend on $\tau_{j}$. for any given $n_{j}$. Let $q_{j}^{*}\left(n_{j}, k_{j}, \theta_{j}\right)$ denote the symmetric equilibrium quantity and $\pi_{j}^{*}\left(n_{j}, k_{j}, \theta_{j}\right)$ denote the equilibrium operative profits, both depending on the number of firms, the level of production costs in industry $j$ and the theta, $\theta_{j}$,parameter.

A firm will find it profitable to enter industry $j$ if and only if:

$$
\Pi_{j}^{*}=\left(1-\tau_{j}\right) \pi_{j}^{*}-F_{j} \geq \overline{\bar{\Pi}}
$$

where $\overline{\bar{\Pi}} \geq 0$ is the outside option.

We look at the equilibrium with free entry. Under the assumption of free entry, $\Pi_{j}^{*}$ is driven to $\overline{\bar{\Pi}}$, meaning that the entry process stops when all the industry specific profit opportunities have been exploited. Since this is true for all industries, no matter 
where a firm decides to enter, the equilibrium profit corresponds to the outside option. By solving (3) for $\pi_{j}^{*}$, we get:

$$
\pi_{j}^{*}=\frac{F_{j}+\overline{\bar{\Pi}}}{1-\tau_{j}}
$$

Clearly, this entry condition will drive a negative relationship between $n_{j}$, via equilibrium profits $\pi_{j}^{*}\left(n_{j}\right)$, the level of fixed cost, the corporation tax and the outside option. The revenue collected by the government in industry $j$, which amounts to $n_{j} \tau_{j} \pi_{j}^{*}$, is supposed to be entirely spent in a productive way. Accordingly, the overall government spending that results is written down as:

$$
G=\sum_{j=1}^{M} n_{j} \frac{\tau_{j}}{1-\tau_{j}}\left(F_{j}+\overline{\bar{\Pi}}\right)
$$

In the equilibrium with free entry, social welfare is given by:

$$
W=G+N \overline{\bar{\Pi}}+C S
$$

where $N \overline{\bar{\Pi}}=\sum_{j=1}^{M} n_{j} \overline{\bar{\Pi}}$ is the sum of all industry profits and $C S=\sum_{j=1}^{M} C S_{j}$ is the aggregate consumers' surplus, with $C S_{j}$ equal to:

$$
C S_{j}=\int_{0}^{Q_{j}} p_{j}\left(Q_{j}\right) d Q_{j}-Q_{j} p\left(Q_{j}\right)
$$

We are interested in characterizing the optimal behavior of a forward looking government seeking to maximize social welfare. By definition, a forward looking government is able to anticipate the number of firms in each industry at the end of the entry process. Let $n_{j}^{L}\left(\tau_{j}, k_{j}, F_{j}, \overline{\bar{\Pi}}, \theta_{j}\right)$ stand for the number of firms operating in equilibrium in industry $j$ as a function of the level of corporation tax, unit cost of production, entry sunk cost, the outside option and theta (intensity of price competition), such that the participation constraint (3) is just binding. In the long run we have:

$$
G=\sum_{j=1}^{M} n_{j}^{L}\left(\ldots, \tau_{j}, \ldots\right) \frac{\tau_{j}}{1-\tau_{j}}\left(F_{j}+\overline{\bar{\Pi}}\right)
$$




$$
\begin{aligned}
N \overline{\bar{\Pi}} & =\sum_{j=1}^{M} n_{j}^{L}\left(\ldots, \tau_{j}, \ldots\right) \overline{\bar{\Pi}} \\
C S_{j} & =\int_{0}^{Q_{j}\left(n_{j}^{L}\right)} p_{j}\left(Q_{j}\left(n_{j}^{L}\right)\right) d Q_{j}-Q_{j}\left(n_{j}^{L}\right) p\left(Q_{j}\left(n_{j}^{L}\right)\right)
\end{aligned}
$$

The government's maximization problem writes:

$$
\mathcal{P}\left\{\begin{array}{l}
\max _{\tau_{1}, \tau_{2}, \ldots, \tau_{M}} W=G+N \overline{\bar{\Pi}}+C S \\
\text { s.t. } \tau_{j} \in[0,1) \text { and } n_{j}=n_{j}^{L}(.)
\end{array}\right.
$$

We are interested in determining the sign of $d \tau_{j}^{*} / d F_{j}$. By solving the above government's problem we get the following:

Proposition 1 The higher the entry sunk cost in industry $j$ the lower the optimal corporation tax rate should be in that industry.

Proof. The generic first order condition of is ${ }^{7}$

$$
\frac{d W}{d \tau_{j}}=\frac{1}{\left(1-\tau_{j}\right)^{2}}\left\{F_{j} n_{j}^{L}-(t-1) \frac{d n_{j}^{L}}{d \tau_{j}}\left[F_{j} \tau_{j}-(t-1) \frac{d C S_{j}}{d Q_{j}} \frac{d Q_{j}}{d n_{j}^{L}}\right]\right\}
$$

In order to assess which is the relationship between the level of optimal corporation tax and the level of entry sunk costs in each industry, by using the implicit function theorem, we can write:

$$
\frac{d \tau_{j}^{*}}{d F_{j}} \propto \frac{d^{2} W}{d \tau_{j} d F_{j}}
$$

Notice that $d^{2} W / d \tau_{j} d F_{j} \propto n_{j}^{L}+A+B$ with

$$
A=\frac{d n_{j}^{L}}{d F_{j}}\left\{F_{j}+\left(1-\tau_{j}\right)^{2}\left[\left(\frac{d Q_{j}}{d n_{j}^{L}}\right)^{2} \frac{d^{2} C S_{j}}{d^{2} Q_{j}}+\frac{d C S_{j}}{d Q_{j}} \frac{d^{2} Q_{j}}{d^{2} n_{j}^{L}}\right] \frac{d n_{j}^{L}}{d \tau_{j}}\right\}
$$

and

$$
B=\left(1-\tau_{j}\right) \tau_{j} \frac{d n_{j}^{L}}{d \tau_{j}}
$$

\footnotetext{
${ }^{7}$ Throughout the paper, second order condition are always satisfied. For the sake of simplicity, without any loss of generality, we have assumed that $\overline{\bar{\Pi}}=0$.
} 
Let us define $\phi_{j}=-d n_{j}^{L} / d F_{j} F_{j} / n_{j}^{L}$ the elasticity of the number of firms w.r.t. the sunk cost in industry $j$. By assuming that $d^{2} C S_{j} / d^{2} Q_{j}<0, \phi_{j}>1$ is sufficient to prove that $d \tau_{j}^{*} / d F_{j}<0$. Assuming that the Sutton $\mathrm{p}(\mathrm{n})$ function is well behaved, we need the optimal number of firms in an industry to respond to the sunk entry cost. In other words we need to assume a certain level of monopolistic power determining short run pricing and entry for our results to hold.

\section{B. Example}

In order to illustrate Proposition 1, let us provide a simple example. The following assumptions are made:

A1: the inverse market demand is $p_{j}=1-Q_{j}$

A2: once in the market, production entails no cost $\left(k_{j}=0\right)$

A3: the outside option $\overline{\bar{\Pi}}$ is normalized to zero

A4: firms compete a la Cournot $\left(\lambda_{j}=1\right)$

After routine computations, the symmetric Nash equilibrium quantity produced by each firm turns out to be:

$$
q_{j}^{*}=\frac{1}{1+n_{j}}
$$

and the associated per firm Nash equilibrium net profits amount to:

$$
\Pi_{j}^{*}=\left(1-\tau_{j}\right)\left(\frac{1}{1+n_{j}}\right)^{2}-F_{j}
$$

A firm decides to enter if and only if $\Pi_{j}^{*} \geq 0$. Under the assumption of free entry, $\Pi_{j}^{*}$ is driven to 0. By solving (13) for $n_{j}$, the resulting number of firms operating in industry $j$ in equilibrium with free entry obtains:

$$
n_{j}^{L}=\sqrt[2]{\frac{1-\tau_{j}}{F_{j}}}-1
$$

As a consequence, in each industry, the lower the corporation tax rate the higher the number of firms in the market. By choosing a small $\tau_{j}$ the government can induce more entry and vice versa. Hence, $\tau_{j}$ becomes a tool to regulate entry. 
Using the definition of public spending (5) and aggregate consumers' surplus (7), social welfare can be written:

$$
W=\sum_{j=1}^{M}\left[n_{j}\left(\tau_{j} \frac{F_{j}}{1-\tau_{j}}\right)+\frac{1}{2}\left(\frac{n_{j}}{1+n_{j}}\right)^{2}\right]
$$

Since the government is forward looking, it is able to anticipate the effect of $\tau_{j}$ on the entry process in each industry correctly, implying that $n_{j}=n_{j}^{L}$. The government's maximization problem becomes:

$$
\mathcal{P}\left\{\begin{array}{l}
\max _{\tau_{1}, \tau_{2}, \ldots, \tau_{M}} W=\sum_{j=1}^{M}\left[\frac{1}{2}+F_{j}\left(1-\sqrt[2]{\frac{1-\tau_{j}}{F_{j}}}-\frac{1}{2\left(1-\tau_{j}\right)}\right)\right] \\
\text { s.t. } \tau_{j} \in[0,1)
\end{array}\right.
$$

The optimal solution to $\mathcal{P}$ is given by:

$$
\tau_{j}^{*}=1-\sqrt[3]{F_{j}}
$$

which always satisfies second order conditions. Clearly, the relationship between $\tau_{j}^{*}$ and $F_{j}$ is negative. ${ }^{8}$

By plugging (16) into (14), the equilibrium number of firms operating in the long run obtains:

$$
n_{j}^{L *}=\frac{1-\sqrt[3]{F_{j}}}{\sqrt[3]{F_{j}}}
$$

By solving (17) for $F_{j}$, and by using symmetry, i.e. the fact that $1 / n_{j}^{L *}$ is the equilibrium market share of each firm in industry $j$, we get:

$$
F_{j}=\frac{H H I_{j}^{3}}{\left(1+H H I_{j}\right)^{3}}
$$

where $H H I_{j}=1 / n_{j}^{L *}$ is the index of market concentration in industry $j$ (HerfindalHirschman Index). Given that $\partial H H I_{j} / \partial F_{j}>0$, the higher the sunk cost, the higher market concentration. By plugging (18) into (16), the expression of optimal corporation tax can be rewritten:

$$
\tau_{j}^{*}=\frac{1}{1+H H I_{j}}
$$

\footnotetext{
${ }^{8}$ The elasticity of $n_{j}^{L}$ with respect to $\tau_{j}$ evaluated at the optimum is $\varepsilon_{j}=1 /\left(2 \sqrt[3]{F_{j}}\right)$.
} 
The following Figure illustrates the relationship between optimal corporation tax and market concentration in industry $j$.

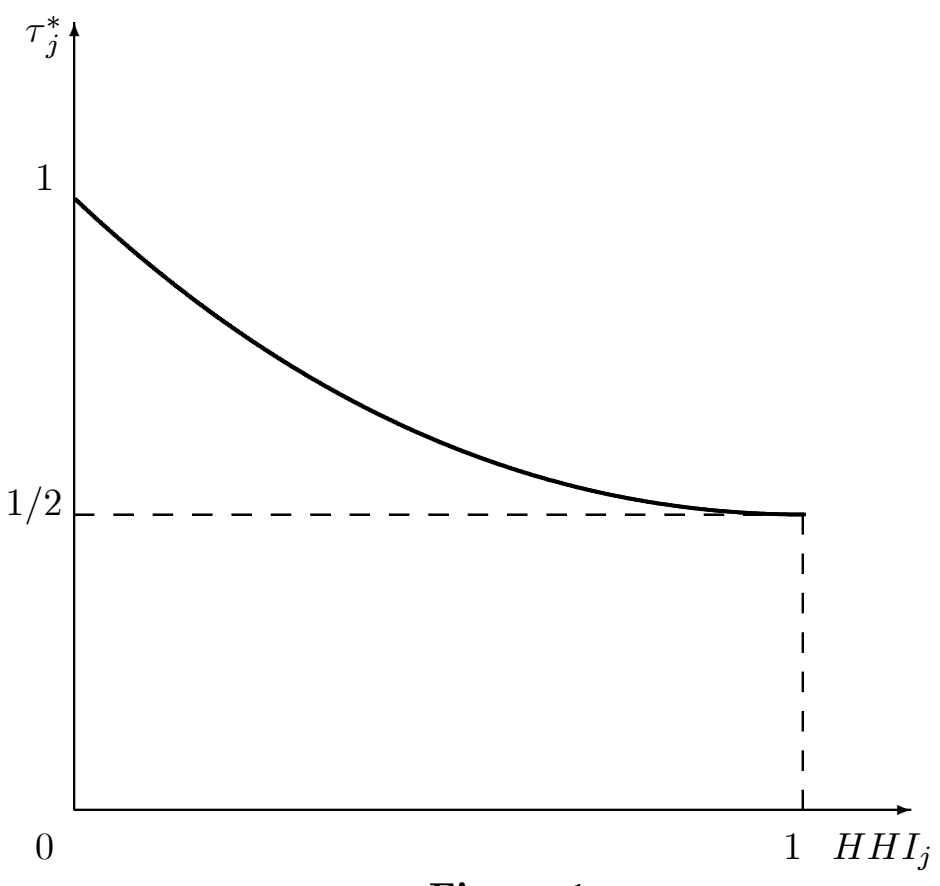

Figure 1

In the equilibrium with free entry:

$$
p_{j}^{L *}=\sqrt[3]{F_{j}} ; Q_{j}^{L *}=1-\sqrt[3]{F_{j}}
$$

while welfare turns out to be:

$$
W^{L *}=\sum_{j=1}^{M}\left[\frac{\sqrt[3]{F_{j}}+2\left(\sqrt[3]{F_{j}}\right)^{4}-3 F_{j}}{2 \sqrt[3]{F_{j}}}\right]
$$

Notice that $\lim _{F_{j} \rightarrow 0} W^{L *} \rightarrow M / 2$, with $\partial W^{L *} / \partial F_{j}<0$. The lower the barriers to entry, the higher the level of social welfare in presence of optimal corporation tax. It is worthy to remark that low barriers to entry are associated with high corporate taxation. In order to restrict entry in a socially desirable way, if $F_{j} \rightarrow 0$ then $\tau_{j}^{*} \rightarrow 1$.

Proposition 2 Under Cournot competition a high sunk cost in industry $j$ (a high $H H I_{j}$ ) yelds a low optimal corporation tax rate to be imposed in that industry. 
Now, let us compare $n_{j}^{L *}$ with (14) when $\tau=0$ :

$$
n_{j}^{N T}=\frac{1}{\sqrt[2]{F_{j}}}-1
$$

where the superscript $N T$ stands for no tax. We can immediately verify that, $n_{j}^{L *}<$ $n_{j}^{N T}$, i.e. the number of firms operating in the long run when an optimal corporation tax is introduced is lower than the number of firms that would have entered the market without taxation. We know from the existing literature that, in absence of taxation, there is an excess of entry with respect to the second best solution.

Let us characterize the second best solution of the entry process. We are about to show that by choosing the optimal level of corporation tax $\tau_{j}^{*}$ it is possible for the government to achieve the socially desirable number of firms in each industry. The government's maximization problem writes:

$$
\mathcal{P}\left\{\begin{array}{l}
\max _{n_{1}, n_{2}, \ldots, n_{M}} W^{S B}=\sum_{j=1}^{M}\left[n_{j}\left(\pi_{j}^{*}-F_{j}\right)+C S_{j}\right] \\
\text { s.t. } n_{j} \geq 1
\end{array}\right.
$$

The optimal solution to is given by:

$$
n_{j}^{S B}=\frac{1}{\sqrt[3]{F_{j}}}-1
$$

which corresponds to $n_{j}^{L *}$.

Proposition 3 A forward looking government may influence the entry process in a way that is socially desirable. The second best solution is achieved by choosing $\tau_{j}^{*}$.

We have shown that in presence of forward looking governments, $\tau_{j}$ can be used in order to regulate the entry process in a socially desirable way. In the next section we will investigate whether the empirical relationship between market concentration and corporation tax is consistent with the principle of taxation derived in this section. 


\section{Stylized Facts}

\section{A. Data Sources}

We use a commercial database of company accounts, sold under the name Amadeus by Bureau Van Dijk. This commercial database of company accounts is comparable to the Compustat database in the US or the Exstat database in the UK. A growing academic literature uses the Amadeus data, (see Budd et al (2002), Konings et al (2001) and Vandenbusshe and Tan (2005)). We use data for companies in 220 NACE Rev1 manufacturing sectors across France, Italy and UK, during three periods 19961998. Companies in the data set have to satisfy at least one of the following criteria: (i) number of employees greater than 100, (ii) total assets exceeding 16 million USD and (iii) operating revenue exceeding 8 million USD respectively. The coverage of medium and large sized enterprises is good in these set of countries. We construct annual measures of effective corporation tax and the HHI of company assets for each NACE sector using, on average, 6,639 French, 7,747 Italian, and 9,077 UK companies.

We measure company size as the value of tangible and intangible fixed assets (in thousands USD). The HHI (Herfindal-Hirschmann Index) is use to measure the concentration of company assets within NACE sectors. We take this to be an outcome of high sector specific sunk costs. Effective corporation tax rate is measured at the overall tax payout over operating revenues (in thousands USD) of each company. Data limitations only allow us to work with the overall tax take and not just the profit tax take. We also prefer to work with a measure of the corporation tax rate as the overall tax payout over operating revenues (in thousands USD), rather than operating profits. We do this for two reasons, tax is overall taxation (not just profit taxation) and sales are reported better than operating profits, less incentives for creative accounting. The idea is to normalize the tax take by the upper bound on tax revenue for each company. Results are not that different if one wished to use operating profits.

The effective corporation tax rate at the sector level is measured as a weighted sum of company effective tax rates (weighted by size of company fixed assets). Across 
sectors differences in effective tax rates result from the different take up of tax allowances, exemptions, and exclusions. Industries with different sunk cost configurations, for example $R \& D$ expenditures, have different abilities to benefit from the tax incentives designed by government. Our measure of the effective corporate tax rate reflects such idiosyncratic features of industries (see MARC, (1999), Gropp and Kostial, (2000) for arguments that explain why company level effective tax rates are different and why they should be used in the construction of industry and country level effective tax rates). Murphy (2005) constructs effective tax rates for countries using the Amadeus data and compares them to alternatives measures and data for EU countries. Levels and trends over the 1990s are very similar.

\section{B. Empirical Results}

Our theory predicts that (optimal) effective industry level corporation tax rates should be negatively related to the concentration of assets within industries (proxy for monopolistic power) Using the Amadeus data we aggregate over companies to construct panel data on ECRTR (effective corporate tax rates) and HHI for around 220 4-digit NACE manufacturing industries in France, Italy and the UK. In Figure 2 we document industry level effective corporate tax rates relative to the overall manufacturing mean. By normalizing 4-digit NACE manufacturing industries corporation tax rates by the overall manufacturing mean within a country, we see clearly, within each country, the co-existence of low and high effective corporation taxation across industries. Industries with different sunk cost configurations have different abilities to benefit from the tax incentives (allowances, exemptions, and exclusions), designed by governments. In Figure 3 we see the spread in the concentration of assets by industry. Industry structure tend to be highly correlated across countries. Due to industry specific sunk cost configurations rather than from any integration process. The question is, do the sunk cost considerations that drive industry structure also drive the level of effective corporate taxation?

In Table 1 we estimate using OLS and GLS (controlling for sector unobservables. with random effects), that industry level effective corporate tax rates are negatively 
correlated with the concentration of assets within industries. Even if one runs company level regressions clustered by industry, controlling for company heterogeneity (age, size, ownership), one still finds a significant negative correlation of effective corporate tax rates with industry level concentration. This is clearly suggestive that our Schumpeterian principle of taxation was used across industries within these countries in the late 1990s.

\section{Conclusions}

Using a Sutton (1991) approach to industry evolution, our IO approach links optimal effective corporation tax rates to the nature of sunk costs within industries. Theory predicts that industry level optimal effective corporation tax rates will be negatively related to the concentration of assets within industries. The principle of taxation is very Schumpeterian, driven by a healthy respect of governments for industry dynamics. In our empirically sections we provide suggestive evidence that this principle of taxation was widely used across industries in France, Italy and the UK in the late 1990s.

Our theory could be extended to test the robustness of this principle of taxation. We feel the presence of endogenous sunk costs or rent seeking sunk cost expenditures (allowing companies to move before the government) would not change the governments incentives to tax concentrated industries softly. Open economy considerations such as the intensity of tax competition over investment flows (the design of financing or R\&D incentives for multinational corporations) are also likely to be related to the nature of industry specific sunk costs leading to further incentives for governments to tax concentrated industries softly. Even though there is a large literature on corporation taxation in Public Finance and International trade, we feel it is not a good idea to ignore industry specific effects, in particular the literature on market structure, in the modelling of effective corporate taxation. 


\section{References}

[1] Altshuler, R., H Grubert and T.S. Newlon (2001), Has US Investment Abroad Become more Sensitive to Tax Rates? In J.R. Hines Jr. (ed) International Taxation and Multinational Activity, University of Chicago Press, Chicago, 9-32.

[2] Anderson, S.P., A. de Palma, B. Kreider (2001), The Efficiency of Indirect Taxes under Imperfect Competition, Journal of Public Economics, 81, 231-251.

[3] Auerbach, A. J. and J.R. Hines Jr. (2002), Taxation and Economic Efficiency, in: Alan J. Auerbach and Martin Feldstein, eds., Handbook of Public Economics, vol. 3 (North-Holland, Amsterdam).

[4] Bresnahan, T. (1989). "Empirical Studies of Industries with Market Power," in Schmalensee and Willig (eds.), Handbook of Industrial Organization, Volume II: 1011-1058. Amsterdam: North-Holland.

[5] Besley, T. (1989), Commodity Taxation and Imperfect Competition: A Note on the Effects of Entry, Journal of Public Economics, 40, 359-367.

[6] Budd, J.W., J. Konings and M.J. Slaughter (2002), International Rent Sharing in Multinational Firms. The National Bureau of Economic Research, Working Paper No. 8809 (Review of Economics and Statistics, forthcoming)

[7] Deasi, M.A., C.F. Foley and J.R. Hines Jr. (2002), Chains of ownership, Regional Tax Competition, and Foreign Direct Investment, National Bureau of Economic Research, Working Paper 6383, Cambridge MA.

[8] Delipalla, S. and M. Keen (1992), The Comparison between Ad Valorem and Specific Taxation under Imperfect Competition, Journal of Public Economics, $49,351-367$.

[9] de Meza, D., J. Maloney, and G.D. Myles (1995), Price-reducing Taxation, Economics Letters, 47, 77-81. 
[10] Galbraith, J.K. (1973), Power and the Useful Economist, American Economic Review, 63, 1-11.

[11] Gropp, R, and K. Kostial (2000), The Disappearing Tax Base: Is Foreign Direct Investment Eroding Corporate Income Taxes? ECB Working paper no 3.1

[12] Grubert, H. and J. Mutti (1991), Taxes, Tariffs and Transfer Pricing in Multinational Corporate Decision Making, Review of Economics and Statistics, 73, 285-293.

[13] Grubert, H. and J. Mutti (2000), Do Taxes Influence where US Corporations Invest? National Tax Journal, 53, 825-839.

[14] J.R. Hines Jr. (1999), Lessons from Behavioral Responses to International taxation, National Tax Journal, 52, 305-322.

[15] Kay, J.A. and M. Keen (1983), How Should Commodities be Taxed?, European Economic Review, 23, 339-358.

[16] Konings, J., P.F. Van Cayseele and F. Warzynski (2001), The Dynamics of Industrial Markups: Using Firm Level Panel Data in Two Small Open Economics to Assess whether Competition Policies Matter, International Journal of Industrial Organization, 19, 841-859.

[17] Mankiw, N.G. and M.D. Whinston (1986), Free Entry and Social Efficiency, Rand Journal of Economics, 17, 48-58.

[18] Martin, S. (1984), A Bainsian Interpretation of Von Weizsäcker's Model of Scale Economies, Southern Economic Journal, 50, 1192-1195.

[19] MARC (1999), Corporate Effective Tax Rates in the European Union, Report commissioned by the Dutch Ministry of Finance.

[20] Myles, G.D. (1989), Ramsey Tax Rules for Economies with Imperfect Competition, Journal of Public Economics, 38, 95-115. 
[21] Murphy, A. (2005), European Foreign Direct Investment: A study of Resource Allocation, Ph.D. Thesis, University of Dublin, Trinity College.

[22] Ramsey, F.P. (1927), A Contribution to the Theory of Taxation, Economic Journal, $37,47-61$.

[23] Schumpeter, J.A. (1942), Capitalism, Socialism and Democracy, New York: Harper \& Row.

[24] Seade, J. (1980a), On the Effects of Entry, Econometrica, 48, 479-489.

[25] Seade, J. (1980b), The Stability of Cournot Revisited, Journal of Economic Theory, 23, 15-26.

[26] Sutton, J. (1991), Sunk Costs and Market Structure: Price Competition, Advertising and the Evolution of Concentration, MIT Press.

[27] Suzumura, K. and K. Kiyono (1987), Entry Barriers and Economic Welfare, Review of Economic Studies, 54, 157-167.

[28] Vandenbussche, H. and C. Tan, The Taxation of Multinationals: Firm Level Evidence for Belgium, LICOS Discussion Paper, K.U. Leuven,160/2005.

[29] Von Weizsäcker, C.C. (1980), A Welfare Analysis of Barriers to Entry, Bell Journal of Economics, 11, 399-420.

[30] Walsh, P.P. and C.Whelan (1999), Loss-Leading and Price Intervention in MultiProduct Retailing: Welfare Outcomes in a Second Best World, The International Review of Law and Economics, 19, 333-347. 
Figure II Distributions in NACE 4-digit industries ECTR's during 1996-1998 relative to 1 (the overall manufacturing mean across Time).
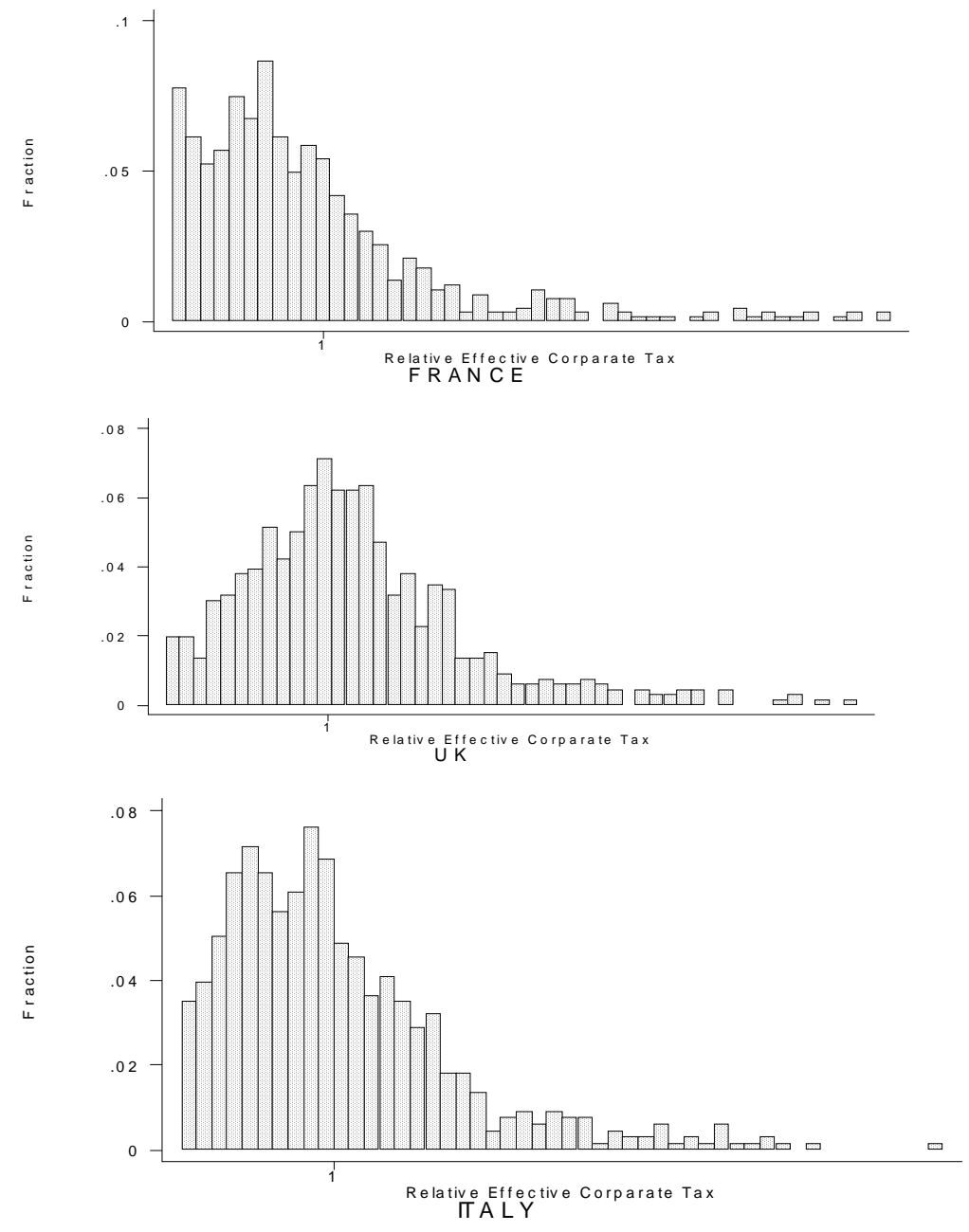
Figure III Distributions of HHI (in company assets) across NACE 4-digit industries 1996-1998
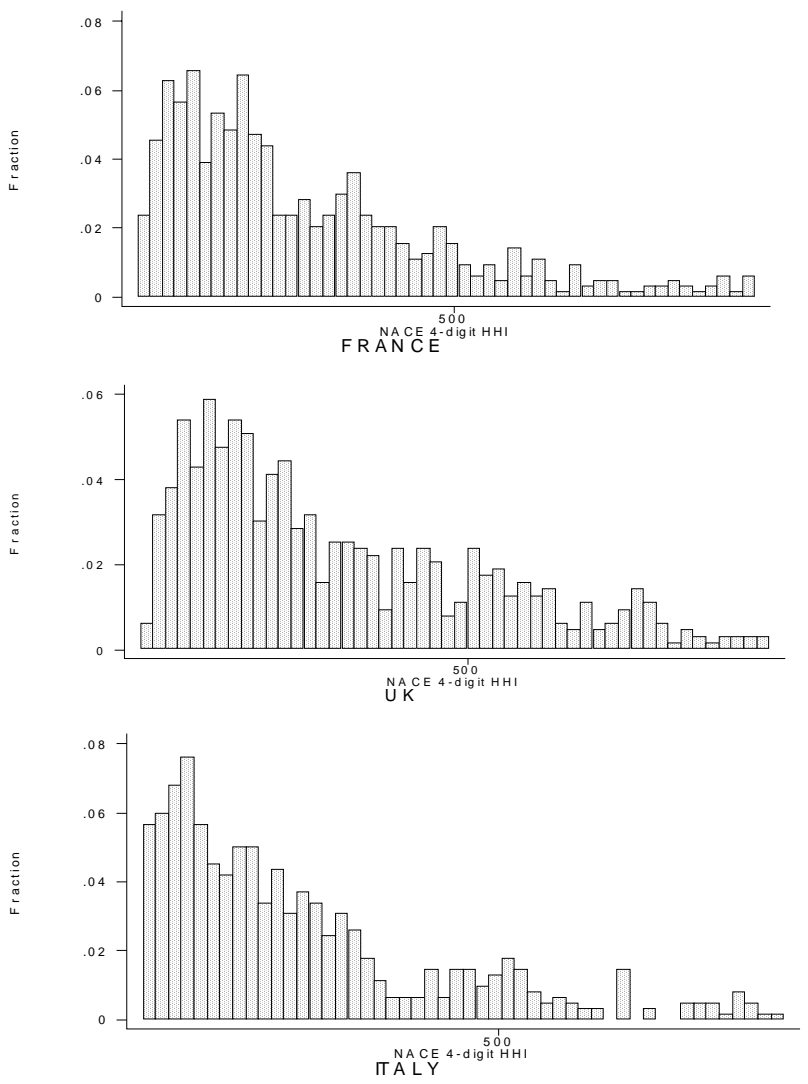

Table 1: Correlations between NACE 4-digit industries ECTR's and HHI's over the period 1996-1998.

\begin{tabular}{|l|c|c|c|c|c|c|}
\hline \multicolumn{1}{|c|}{ In (ECTR) } & \multicolumn{2}{c|}{ France } & \multicolumn{2}{c|}{ Italy } & \multicolumn{2}{c|}{ UK } \\
\hline & OLS & G LS & OLS & GLS & OLS & GLS \\
\hline $\mathbf{R}^{2}$ & .10 & .10 & .11 & .11 & .10 & .10 \\
\hline Constant & 1.9 & 1.9 & 1.3 & 1.3 & .76 & .75 \\
& $(6.5)$ & $(4.8)$ & $(6.8)$ & $(4.9)$ & $(11.9)$ & $(11.3)$ \\
\hline In (HHI) & -.38 & -.35 & -.22 & -.21 & -.28 & -.24 \\
& $\mathbf{( 6 . 8 )}$ & $\mathbf{( 5 . 0 )}$ & $\mathbf{( 6 . 0 )}$ & $\mathbf{( 4 . 2 2 )}$ & $\mathbf{( 3 . 5 )}$ & $(\mathbf{2 . 6 )}$ \\
\hline Time Dumm ies & Yes & Yes & Yes & Yes & Yes & Yes \\
\hline Random Effects & No & Yes & No & Yes & No & Yes \\
\hline \# 4-digit NACE & 227 & 227 & 220 & 220 & 223 & 223 \\
\hline \# of Observations & 673 & 670 & 658 & 655 & 662 & 659 \\
\hline
\end{tabular}

